\title{
LA SANIDAD NACIONAL Y LAS ENTIDADES LOCALES
}

Hay que convenir en que la tan discutida Ley llamada de "coordinación sanitaria" ha tenido muy poca eficacia para asegurar el pago puntual de los médicos titulares, que fué, en fin de cuentas, sú verdadera finalidad.

Pero, en cambio, lo que la Ley se proponía accesoriamente, que era fomentar la creación y el desarrollo de los centros sanitarios provinciales incluyéndolos en las Mancomunidades, lo ha conseguido muy bien.

Conviene recordar que a fines del siglo pasado nuestro país carecía totalmente de organización sanitaria, porque no puede reputarse como tal a los Subdelegados de Medicina, funcionarios entonces con más sabor político que técnico, nombrados libremente y a las órdenes del Delegado o Jefe político, que acudía a ellos en caso de anormalidad sanitaria, más para cubrir aparentemente su responsabilidad que para luchar realmente contra las epidemias tan frecuentes por entonces.

Fué en los primeros años de la actual centuria cuando se creyó necesario elevar el nivel técnico de los cargos sanitarios al mismo tiempo que se les independizaba, en la medida de lo entonces posible, de las presiones políticas, y fué entonces también cuando mediante oposición se cubrieron las 49 plazas de Inspectores Provinciales de Sanidad, muy poco tiempo antes de la aprobación de la Instrucción General de Sanidad de Cortezo y Maura.

Significaba esto, evidentemente, un progreso, un primer paso, en la organización sanitaria, pero nada más que esto. En primer lugar, no se podía exigir a los recién nombrados grandes conocimientos sanitarios, que por entonces era imposible adquirir dentro de nuestro país. Por otra parte, aquellos 49 Inspectores Provinciales 493 
no eran otra cosa más que consejeros de los Gobernadores Civiles, a los cuales asesoraban en materias sanitarias. Tenían, indudablemente, más convcimientos que los antiguos Subdelegados y aun poseían mejor voluntad. Pero ni con una ni con otra cosa era bastante para resolver ios problemas sanitarios, y aquellos hombres, a los que debemos gratitud porque fundaron nuestros actuales servicios, en realidad, hicieron muy poco. Así se comprendió por los gobernantes años después y surgió una organización de Institutos sanitarios regionales, que se distribuían el servicio de las distintas provincias españolas y que en realidad no pasó de ser un buen propósito, cayendo poco a poco en el olvido sin haber sido cumplimentacia jamás.

En cambio, al margen de la legislación e impuestas por las necesidades cada vez más patentes, surgieron poco después las llamadas "Brigadas Sanitarias", que prestaron servicios muy estimables, y, lo que es más importante, que constituyeron el embrión de donde salieron los actuales Institutos de Sanidad Provinciales.

La vida de estos Institutos fué lánguida hasta la aparición, primero, del Yeglamento de Sanidad Provincial de Calvo Sotelo, en que pasaron a ias Diputaciones Provinciales, pero sobre todo a partir de la Ley de Coordinación Sanitaria, en que progresaron de tal forma, que actualmente son una minoría las provincias que no poseen magníficos Centros y aún en éstas se tiene el propósito de mejorarlos o construirios de nuevo. Pero entendamos bien que el problema no está resuelto totalmente, sino en vías de solución, y que los Centros actuaies tienen defectos que hay que remediar encaminándolos a la perfección. Yo creo que escribir un artículo para alabar lo existente no tiene otra ventaja que la ejemplar, y me parece más útil decir cuáles son los actuales defectos de los Institutos para ir tratando poco a poco de modificarlos y conseguir que, de la misma manera que hay una gran diferencia entre los Servicios Sanitarios de 1900 y los actuales, debemos aspirar a que en años venideros se continúe la mejora y se reconozca el esfuerzo que hemos realizado siempre hacia la perfección.

Por mi parte, hay dos grandes problemas de organización provincial que me han preocupado y me siguen preocupando porque no están bien planteados aún. El primero es la fusión de los Servicios Sanitarios Municipales con los Provinciales. El segundo es el dotar a los Servicios de una verdadera eficacia que les permite desenvolverse con completa autonomía dentro de su zona de accibn. Por lo que atañe al primero, la fusión del Laboratorio Municipal de Madrid 494 con el Instituto de Higiene de la provincia ha sido evidentemente 
un fracaso que no es posible disimular, porque la derogación del Decreto en que se establecía es sufieientemente elocuente para que quiera paliarse. $Y$, sin embargo, estoy convencido de que estábamos, por muchas razones, en el buen camino. Ciertamente que se trataba de una reforma muy delicada por la cantidad de intereses que se iban a herir, unas veces, en el aspecto económico; otras, en el de la vanidad, que en ccasiones es más temible que aquéllos. Era, pues, fácilmente previsible que cortra la fusión iban a arremeter una gran cantidad de influencias y de presiones. Por otria parte, también era cierto que el Ayuntamiento de Madrid, un poco descuióado en modernizar sus servieios sanitarios, tenía a su favor el haberlos implantado antes que los de la provincia y que difícilmente se resignaría a perder esta parte de su historia sanitaria, que casi constituía una tradición en que la que abundaban páginas muy estimables y nombres gloriosos. La fusión exigía, pues, una discreción, una cautela y una lentitud incompatible con impaciencias y con el deseo de autonomía y aún de independencia sanitaria que tanto se predica en la actualidad. $Y$ nosotros estábamos más obligados que nadie a tenerla, no sólo por el respeto a la Corporación Municipal, sino por la trascendencia de la carta sanitaria que jugábamos, ya que de triunfar la reforma en Madrid se extendería fatalmente a todas las provincias españolas.

Ya hubo un error inicial en la redacción del Decreto al no respetar total y generosamente todos los derechos adquiridos, aún los dudosos, pensando en que una reforma de este calibre, unos años más no significan absolutamente nada y que es preferible avanzar con lentitud que no exponerse a un paso atrás, que es lo que ha pasado, y es preferible, porque corregir este error va a costar mucho más tiempo que el que hubiéramos perdido en reconocer otros derechos. Fué otra equivocación el no dar al Ayuntamiento la garantía absoluta de que con la fusión de servicios no perdía nada de sus derechos, de sus prestigios, ni de sus fueros. Por todo esto, yo sigo creyendo que es un absurdo que, a estas alturas, continúen separados los Servicios Sanitarios de las provincias y de sus capitales y que quizás todo podría obviarse estrechando más los lazos entre los servicios del Estado y los municipales. Ya, por ejemplo, lss Diputaciones no se acuerdan de que los Institutos Provinciales les pertenecieron durante algún tiempo y no piersan en rescatarlos, convencidos de que están mejor y son más útiles ahora que antes. Con los Ayuntamientos pasaría exactamente igual.

El segundo punto a que antes he aludido es la eficacia de los 495 
Institutos Provinciales. Desde luego, todos estamos conformes con que los actuales servicios son incomparablemente mejores que los de 1900 y aún que los de 1930. Pero sería muy interesante saber si hay paralelismo entre la mejora de servicios y el aumento de los presupuestos. Creo que sería conveniente revisar lo que se invierte en personal y lo que se destina a material. Bien entendido que al personal se le debe pagar bien, pero tratando de reducir su número, que en ocasiones pudiera ser excesivo, anulando la tendencia constante a aumentarlo sin reflexionar en que mientras mayor sea su número más difícil será el retribuirlo con suficiencia.

La rapidez actual de las comunicaciones modifica también el concepto que antes merecían estos Centros. En la mayor parte de ellos es innecesaria la fabricación, desde luego, de sueros, pero también de vacunas, que se puede conservar exclusivamente para los más fuertes económicamente o para los mejor situados. En cambio, el hacerles que contribuyan a los gastos que origina la medicación antivenérea, o, en su caso, a la antipalúdica, me parece convenientísimo.

Hay que estudiar también la manera de aumentar el apoyo que desde las Mancomunidades se presta a los Centros Secundarios y a los Primarios, logrando así una red de policonsultorios en los que se basa actualmente toda acción sanitaria.

Por último, es conveniente ir estudiando las modificaciones que en los Institutos de Sanidad deben introducirse para ponerlos de acuerdo con el Seguro de Enfermedad. Si éste no se preocupa de la tarea de prevenir las enfermedades irá irremisiblemente a la ruina. El trabajo de nuestros dispensarios de Puericultura, Venéreo, de Tuberculosis, de Tracoma, etc., tienen que favorecer enormemente a la Entidad aseguradora y tendrá a su vez que ser favorecido por ella. En realidad, el Seguro de Enfermedad va a modificar esencialmente todas las Organizaciones Sanitarias Municipales y ProvinciaIEs, $y$ por ello es hora ya de que pensemos seriamente en acoplarlas a este nıevo sistema, que urge conocer, porque de él derivarán las nuevas normas de organización. 